\title{
Unexpected Benefits of Voice Type Computing Douglas R.Bowes
}

\author{
Special Education Technology British Columbia \\ Victoria British Columbia V8R 4C5, Canada
}

\begin{abstract}
Six of seven grade school students using Voice Type Voice Data entry systems experienced a variety of unexpected learning. Improvements in speech, breathing patterns, stamina and overall communication were noted in six of the participants. This paper looks at the partnership that produced this result as well as case synopsis for six of the users
\end{abstract}

\section{Introduction}

The Voice Project is a cooperative study among British Columbia schools and students, IBM Canada, and Special Education Technology -British Columbia (SET-BC) . Funding for the specialised equipment was provided by the Woodward foundation. IBM Canada provided technical and equipment support, SET-BC provided equipment, technical administrative and travel support and a speech therapist/technology consultant for research design and student training/support.

The objective of the project was to put Voice Input computing technology (Voice Type $^{\mathrm{TM}}$ voice data entry) into British Columbian schools so that students with disabilities have the opportunity to produce their written work independently. The secondary objective of the project was to learn what adaptations had to be made to the equipment, to student training and to work environment so that users with speech disabilities could use it as an effective education tool.

Seven Computers adapted using M-ACPA ${ }^{\mathrm{TM}}$ speech recognition cards and IBM Voice Type $^{\mathrm{TM}}$ Software were offered to students participants with physical handicaps in all regions of British Columbia. Students using the above configured computers can cause any keyboard command to be entered into the computer by using their voice. The student merely dictates his written work into a microphone and the computer transcribes it into a word processing (database or spreadsheet) document .

\section{Objectives:}

2.1 To allow the student participants to produce their written communication and written school work independently

2.2 To make the necessary adaptations to software, hardware and training methods so that students with specific disabilities could use this technology effectively and,

2.3 To examine if any improvements in oral communication (speech) occurred as a result of using Voice Type. 


\section{Measurement and Achievement of Objectives}

The seven students in this project have a variety of disabling conditions including cerebral palsy, muscular dystrophy, and ALS (Lou Gerhig's Disease) and come from Elementary and Junior High Schools across the province. All of the participating students have great difficulty producing their written work without assistance, and most have significant speech difficulties that affect intelligibility.

All of the students increased their ability to produce written work significantly. Most of the students tripled their WPM output with one improving by $25 \%$. Other benefits included increased speech intelligibility and endurance (see case studies).

\section{Case Studies}

Student S: As well as tripling her WPM, she used the Voice Type as an adjunct to speech therapy for the correction of a lateral lisp. The strategy involved using Voice Type to reinforce correct production of her $/ \mathrm{s} / \& / \mathrm{z} /$ sounds. A Voice Type training session would follow a speech therapy session. If her speech production was good, the Voice Type would recognize the word, if not she had to delete it and repeat it "correctly' for the computer to understand. Initially, this approach yielded some good results, however, the effort required to do both speech therapy and Voice Type training in a short period of time proved to be too physically demanding for this student participant. This student carried on with Voice Type successfully, but probably has not made any permanent changes to her speech patterns. It is felt that the trial period was not long enough to successfully test the Voice Type as a therapy adjunct. (other potential Voice Type user have indicated that they are interested in exploring this approach)

Student $K$ : This student increased her output from 7 to 23 WPM. Her ability and desire to produce written communication are demonstrated through her perseverance (as well as through the efforts of her school based team) in relearning the system after a severe deterioration in her health. Her illness required emergency medical treatment which caused a memory loss that resulted in her inability to use the Voice Type system upon return from hospital. This student and her team worked hard and soon relearned the system. $\mathrm{K}$, a grade 6 student has recently written a short book 32 pages on her love of horses. Speech is only a peripheral issue for this student as her disability only had a marginal effect on intelligibility.

Student L: As well as tripling her WPM, L could use the Voice Type as an interpreter for those who couldn't understand her speech patterns. (The Voice Type understood her speech when others did not.) The computer had to be trained to ignore random respiratory noises that she made and the Voice Type rejection threshold had to be altered. The physical effort of speaking make it difficult for her to use the Voice Type for lengths of time greater than 20 minutes. Her use of the product is being reviewed by her school based team.

Student S2: Voice Type increased his output by 5 WPM. He felt that the 5 WPM did not justify his continued use of the Voice Type. He is striving to improve his adapted access on a regular keyboard. He feels good having explored the possibilities of Voice Input computing and is confident that he will do better with an adapted keyboard 
Student A: Increased his output from 8 to 22 WPM and continues to use the system. Student $\mathrm{A}$ is a new addition to the program and little data is available at this time.

Student J: This student's breathing patterns were so inefficient (shoulder clavicular) that initially he lacked the breath and stamina to even begin training the computer. Amplification of his voice proved to be ineffective as it also amplified environmental and respiratory noise. Initial training sessions were also limited to 10 minutes because the student's stamina and endurance were low. Modified training sessions involved lying the student on his back to diminish the effects of gravity and inhibit his shoulder clavicular breathing. Diaphragmatic breathing patterns were taught while training the initial Voice Type vocabulary. Modifications to the Voice Type parameters include increasing the word duration and decreasing the rejection threshold. As well as being able to produce his written work when using Voice Type, this student can monitor his speech and breathing patterns as a function of how well the computer understood his speech patterns. If the computer doesn't understand, then he has to modify his breathing patterns. J increased his WPM from 4 to 12.

Student $J 2$ had the most difficulty with the system. J2's education to date had him placed in special needs classes. Because of severe motor and vision difficulties, reading was well below his junior high placement. Instead of Word Perfect, this student used IBM's Primary Editor Plus as his Word Processor. J2 proved to have a very low literacy level, probably because of his poor speech, low vision and lack of attainable challenges. Training started with Dolch Vocabulary lists. Sight Vocabulary showed a significant increase during the initial stages of his participation.

This student transferred to another school district in the fall of 1993 and ceased using Voice Type because of a lack of trained support in his new district.

\section{Average Change in Quantity of Written Output (WPM)}

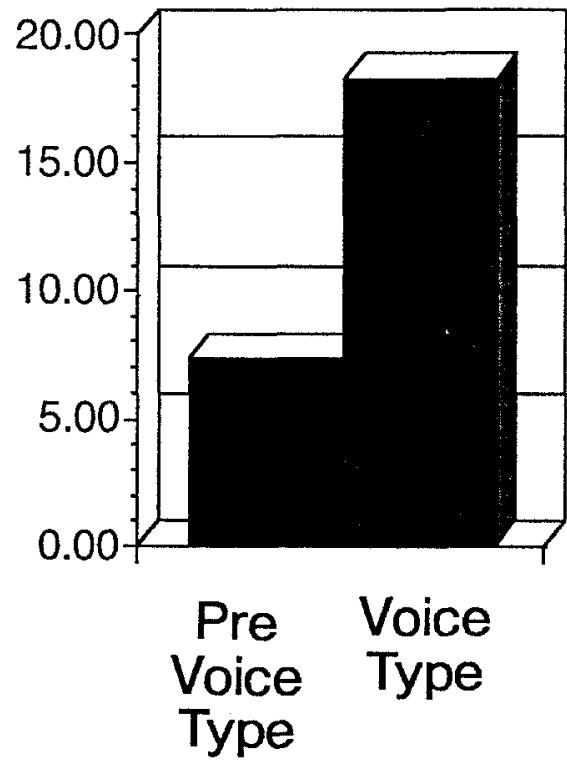




\section{Benefits of Project}

In Canada It is a fair assumption that jobs in the year 2000 and beyond will require much more technical savvy than jobs held by previous generations. As Canada turns from resource based industry to technical and manufacturing industries, employers will be looking for a new type of worker. More important than an individuals physical ability will be their intellectual skills and ability to interact with technology. Students participants in this project have access to technology that can make them competitive in the classroom and the workplace. This technology and it's future iterations will allow employers access to some great minds that might not otherwise be considered for employment because of the physical limitations of their bodies.

\section{Change in Quantity of Written Work (WPM by student)}

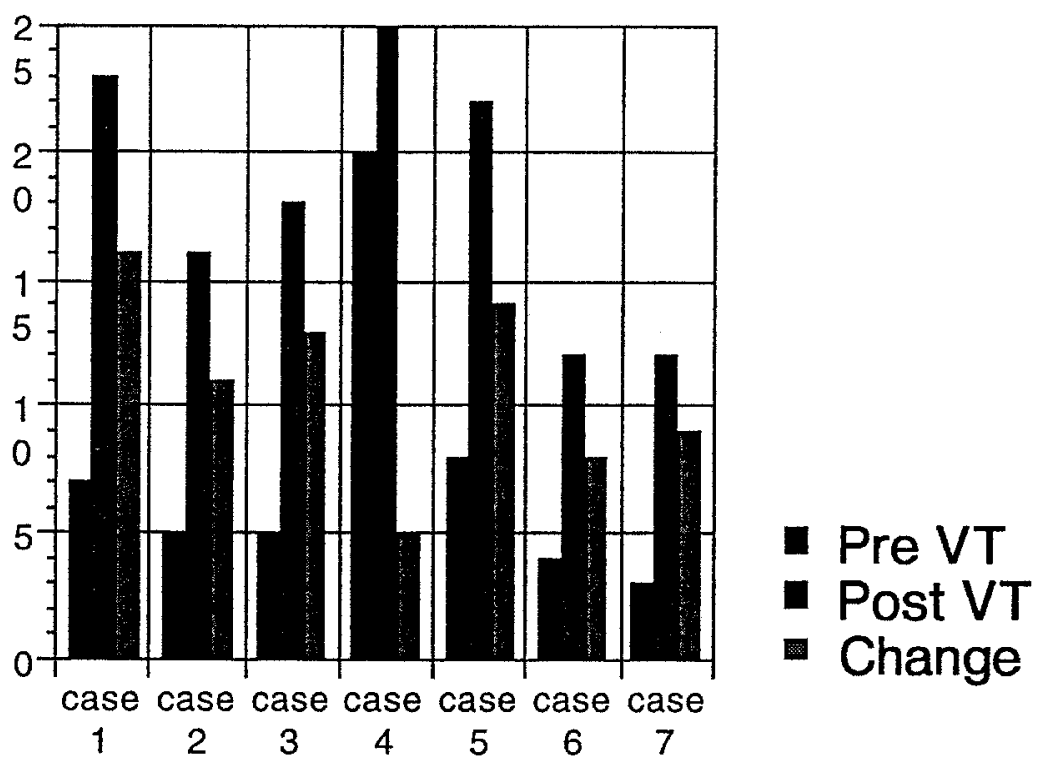

On average participating students using Voice type more than tripled their written output compared to previous methods using adapted computers. All but one of the students acquired the skills necessary to produce their written work independently. This was achieved by modifying word pause, rejection thresholds, posture, seating, breathing patterns and the training routines. Beyond increasing the amount of their written work produced independently, some of the student participants demonstrated an improved speech intelligibility and increased stamina (breathing and speaking). 


\section{Benefits of the Project to the educational institutions}

Any school benefits when a project helps them realise their goal of of helping to make their students independent members in the community. By participating in the project the participating schools helped to remove a barrier to independent learning for their students. Most of these students used an adult scribe to produce their written work prior using the Voice Type system. When the student participant wasn't using the Voice Type system teachers and other students were encouraged to explore its potential for use with the student participant's classmates. Learning Disabled students and English as a second language students also made use of the equipment.

to the students The opportunity for student participants to participate more completely in their education is a goal that is more readily attainable because of Voice Type. Most students indicated that technology like Voice Type will be a significant factor once they graduate and seek employment.

to the teachers Any learning tool that serves a student through their school experience and leads to independent learning is welcomed by teachers. One of the first things a student is taught in school is how to write. This valuable learning and communication tool is denied to those students whose bodies cannot allow them to use a pen or pencil. The Voice project allowed these students to use Voice Type as an electronic pencil to write easily and intuitively for the first time in their lives.

to the parents Every parent wants to see their child succeed. None are more committed to the success of their child than the parents of a student with a physical handicap. The Voice project has helped to remove one obstacle to success for their child and offered a larger measure of independence for that child.

to society One of the great minds of this century is trapped inside a barely functioning body. Steven Hawking's insights into the nature of space and time would not be known today if computer technology was not adapted to allow him to communicate his ideas with the world. This project has allowed seven students another way to communicate their thoughts with the world. Time will tell if the their words will be heard as far and wide as Steven Hawking's.

\section{Development of Long Term Relationships between business and Education}

SET-BC and IBM Canada are now exploring the use of Voice Type 2 as a written communication platform for secondary and post secondary students in British Columbia. Preliminary data suggests that the new training module for Voice Type 2 significantly cuts down on the amount of training for users of Voice Type. SET- BC is now actively using a number of IBM products in BC schools for Visually Impaired students, physically challenged and speech Impaired students. SET-BC is exploring a project with GUS Robotics and IBM Canada to produce a made in Canada VOCA (Voice Output Communication Aid) for the speechless around the world. A prototype has been produced and trials are beginning at this time. 